Jorge Costadoat, S.J.

Profesor de la Facultad de Teología

Pontificia Universidad Católica de Chile

\title{
Los "signos de los tiempos" en la Teología de la liberación
}

La teología de los "signos de los tiempos" representa una verdadera novedad de la teología del siglo XX. A ella la Teología de la liberación le debe la inspiración y el método (1).

Juntamente con Medellín, la Teología de la liberación recibe el Concilio Vaticano II de un modo creativo precisamente porque, a semejanza de Gaudium et Spes que pone a la Iglesia a la escucha de la voz de Dios en la historia, ella nace de una Iglesia que reconoce en los pobres del continente un llamado divino a su liberación (2). "Los signos de los tiempos" representan para la Iglesia continental, y para la Teología de la liberación particularmente, un modo de ubicarse en su propio mundo latinoamericano en busca de la presencia y de la voluntad de Dios (3). Por lo mismo la categoría hace las veces de supuesto fundamental de un movimiento eclesial polisemántico por naturaleza y de paradigma metodológico clave de la primera teología que pretende ser realmente latinoamericana (4).

(1) La teología de los "signos de los tiempos" ha sido discutida por la vaguedad de su concepto. También en la Teología de la liberación hay conciencia de la dificultad para hablar teológicamente de "signos de los tiempos". Clodovis Boff llega incluso a proponer, como alternativa, hablar de una "Teología 2" (T2), "para indicar a teología que se ocupa de todos os problemas referentes à secularidade, sobre todo dos problemas sociais" (Clodovis Boff, Sinais dos tempos, Ediçôes Loyola, Sâo Paulo, 1979, p. 161).

(2) Cf. CELAM: el "Mensaje a los pueblos de América Latina" (Medellín / 1968).

(3) El texto conciliar habla de "signos" que indican la "presencia" y los "planes de Dios" en la historia. Qué ha puede significar esa "presencia”, es objeto de discusión. La Teología de la liberación, en cuanto teología de la praxis y especialmente en el caso de teólogos jesuitas formados en la fragua de los Ejercicios de San Ignacio, subrayará que los signos de los tiempos se relacionan con la "voluntad" de Dios (cf. Miguel A. Fiorito y Daniel Gil "Signos de los tiempos, signos de Dios. Apuntes para una teología, una espiritualidad y una pastoral de los signos de los tiempos", Stromata 32 (1976), 3-95).

(4) Jon Sobrino pretende "mostrar el hecho de que la Teología de la liberación toma absolutamente en serio los signos de los tiempos y las implicaciones que eso tiene para el quehacer teológico y para la comprensión de lo que es ese quehacer" (Jon Sobrino "Los 'signos de los tiempos' en la teología de la liberación”, Estudios Eclesiásticos 64 (1989) 249; Juan Noemi destaca la importancia del hecho de que por primera vez en América Latina surge una teología propiamente latinoamericana y, además, porque tiene como objeto propio la historia actual del continente. No obstante la precariedad de sus ensayos, su propósito de convertirse en teología de la historia apunta en la dirección correcta (Juan Noemi, reseña al libro de Samuel Yáñez y Diego García (eds.) El porvenir de los católicos latinoamericanos, Universidad Alberto Hurtado, Santiago, 2006, redactada como "reflexión elemental”, publicada en Teología y Vida, Vol. XLVI (2007, 105-110). 
En este artículo se destaca la importancia de los "signos de los tiempos" para el método de la Teología de la liberación; se explicitan los principales supuestos teológicos de esta teología; y se remata con el que sería el "signo de los tiempos" en América Latina, la irrupción de los pobres.

\section{CAMBIO DE PARADIGMA TEOLÓGICO}

La recepción latinoamericana del concepto de "signos de los tiempos" representa para la Teología de la liberación el punto de quiebre respecto de la teología europea tradicional (5). Jon Sobrino habla de "ruptura epistemológica" (6). Ella ha sido propiciada por el cambio de paradigma teológico inaugurado en el Vaticano II (7). En realidad, más que una ruptura se trata del comienzo de una teología que no es latinoamericana por el lugar geográfico de su producción, sino porque su objeto es la historia actual de América Latina (8). Los teólogos de la liberación son tajantes al decir que la suya es "una nueva manera de hacer teología" (9). Ella se beneficia del aporte de la Hermenéutica (10). En términos simples, la diferencia estriba en que el "texto" que la teología pretende leer, reflexionar y comprender no es en primer lugar el texto de la Sagrada Escritura (conservada y trasmitida por la Iglesia en sus diversos textos magisteriales, litúrgicos, etc.), sino la historia misma en la cual Dios aún se revela en Cristo a través del Espíritu (11). A saber, la historia en la que la praxis liberadora de los pobres, de la cual ellos son objeto y sujetos de liberación, revela la acción espiritual inmanente de Dios. De aquí que Gustavo Gutiérrez, al definir su teología, distingue un "acto primero", consistente en la práctica cristiana liberadora (12); y un "acto segundo", la teología estricta, como "reflexión crítica de la praxis histórica a la luz de la Palabra" (13).

(5) La teología europea de vanguardia, en tensión con la teología neoescolástica, ha profundizado en la concepción histórica de la teología. Recientemente Peter Hünermann afirma: "Si la teología es, pues, intellectus fidei, de allí se desprende, ante todo, que la teología cristiana es fundamentalmente interpretatio temporis. Esta interpretatio temporis encierra consigo todo aquello que se da en el tiempo, pero no se mueve simplemente en el nivel de los anales, de la ciencia histórica" (J.O. Beozzo, P. Hünermann, C. Schickendantz, Nueva pobrezas e identidades emergentes, Editorial Universidad Católica, Córdoba, 2006, 56).

(6) Jon Sobrino, Jesucristo liberador, Trotta, Madrid, 1991, p. 52.

(7) Cf., Carlos Casale "Teología de los signos de los tiempos. Antecedentes y prospectivas del Concilio Vaticano II", Teología y Vida, Vol. XLVI (2005), 527-569.

(8) Como otros autores, Sobrino recoge las referencias conciliares que GS hace a los "signos de los tiempos", de acuerdo a las cuales estos pueden ser comprendidos de un modo histórico-pastoral (GS 4), como contexto que la Iglesia debe considerar en su labor evangelizadora, y también de un modo histórico-teologal (GS 11), como acciones, hechos, acontecimientos históricos que hacen sacramentalmente presente a Dios y a su voluntad ("Los 'signos de los tiempos' en la teología de la liberación”, o.c., pp. 250-251). La nota característica de la teología de la liberación es entender los "signos de los tiempos" en este último sentido. Se ha dicho de ella que es la "primera teología no europea" (cf. J.O. Beozzo, et al., o.c., p. 104).

(9) Gustavo Gutiérrez, Teología de la liberación. Perspectivas, Sígueme, Salamanca, 1990, p. 72.

(10) Cf. Eduardo Silva "Auscultar los signos del tiempo presente y de la situación latinoamericana. Esbozo de algunos fenómenos a considerar para una interpretación teológica del presente", Teología y Vida, Vol. XLVI (2005), 582-614.

(11) Clodovis Boff, o.c., p. 162; Jon Sobrino, o.c., p. 265-266.

(12) Clodovis Boff, o.c. p. 157.

(13) G. Gutiérrez, o.c., p. 70. 
Esto no significa que la Teología de la liberación menosprecie la enseñanza tradicional de la Iglesia, y menos aún del Evangelio. Algo así sería para los teólogos de la liberación una verdadera locura. La diferencia está en que, para estos, el Evangelio no puede sino ser una noticia liberadora de Dios para los hombres y mujeres de hoy, especialmente para los más pobres, lo cual no consiste primariamente en una enseñanza teológica que creer sino en una acción real y actual de Dios en la misma historia (14). Pero como Dios "no mete mano" en el mundo, sino que actúa en la historia "espiritualmente" a través de las libertades, no es obvio que toda acción humana sea también de Dios (15). Ella exige un discernimiento que se realiza teniendo a Cristo como criterio y al Espíritu Santo como voz nueva, siempre creativa y liberadora, de la voluntad de Dios. Es más, la Teología de la liberación apuesta a que el depósito de la fe, gracias a circularidad hermenéutica entre el credo y el creyente, es aún mejor comprendido que aquella comprensión de los textos fundamentales del cristianismo ofrecida por teólogos que, a lo más, son influidos por su contexto sin que este, en cuanto tal, sea objeto de indagación teológica (16).

Una diferencia metodológica principal de la Teología de la liberación, derivada precisamente por la solicitud por responder "a los signos de los tiempos", consiste en exigir fe al teólogo como condición indispensable de su quehacer científico. Jon Sobrino lo tiene muy claro: "En la teología de la liberación está actuante la fe en cuanto acepta y asume los contenidos de la fides quae (a pesar de lo que se suele decir en contra), pero está actuante la fides qua de forma precisa. En ese acto de creer, cree que Dios sigue presente en la historia, cree en el actual señorío de Cristo, cree en el Espíritu presente como principio de realidad, de verdad y de novedad. Pero esta creencia no es solo considerada como un contenido de esta teología, sino que es ante todo una realidad aceptada y experimentada in actu por el teólogo como tal. Hacer teología es entonces inteligir esa presencia de Dios en la historia en cuanto presencia actual" (17). En otras teologías la fe del teólogo es un desideratum,

(14) No se puede pasar aquí por alto la reciente Notificación de la Congregación para la Doctrina de la Fe a la cristología de Jon Sobrino. La primera de las objeciones se refiere al método de esta cristología. Se objeta que el autor suplante en cierto sentido la fe de la Iglesia por la "la Iglesia de los pobres" en cuanto lugar teológico. De momento baste decir -porque no es este el lugar para extenderse en ello- que Sobrino no prescinde de la fe de la Iglesia (fides quae), sino que subraya la importancia de la fe actual de los cristianos (fides qua) tenida en un contexto determinado en orden a sacar las consecuencias liberadoras de la fe de la Iglesia. Este fin es compartido por la Congregación en la nota aclaratoria a la Notificación.

(15) Pedro Trigo sostiene que "(1)a pregunta por el discernimiento de la acción del Espíritu Santo en la historia solo tiene sentido si el Espíritu actúa en la historia y su acción no es ni tan palmaria que no haya nada que discernir, ni tan impenetrable que no deja ningún indicio para rastrearla". Dios no es mundano, pero, amándonos, actúa en el mundo a través de acciones humanas. El "no mete la mano en el mundo", sino que actúa en el mundo en virtud de una relación "absolutamente trascendente y libre..." (Pedro Trigo "El discernimiento de la acción del espíritu en la historia", ITER No 33 (2004) 40-41.

(16) Cf. Jon Sobrino "Los 'signos de los tiempos' en la teología de la liberación”, o.c., 263-265.

(17) Ibidem, p. 251-252. Para Juan Carlos Scannone el requisito de la fe en la captación de los "signos de los tiempos", en el método de GS y en la Teología de la liberación, es decisivo para que haya teología propiamente tal. Lo afirma en contra de quienes han podido pensar que el momento del "ver" la realidad depende de las ciencias sociales (cf. Juan Carlos Scannone, "La recepción del método de 'Gaudium et Spes' en América Latina”, AAVV La constitución Gaudium et Spes. A los treinta años de su promulgación, San Pablo, Buenos Aires, 1995). 
pero puede ser también un estorbo. Este es el precio, parece, que la teología debe pagar para ser reconocida entre las ciencias modernas. La neutralidad de la reflexión científica subyace a la teología moderna como un requisito de sobriedad, como una moderación a la emotividad creyente, pero acaba por desplazar a la fe del teólogo a un lugar secundario. Para la Teología de la liberación, en cambio, de la fe del teólogo que cree junto con otros, en comunidades y en la tradición de la Iglesia, constituye un principio epistemológico decisivo de la circularidad hermenéutica que ha de establecerse entre Dios que se reveló en Jesús en el pasado y que continúa revelándose espiritualmente en Cristo en el presente. Para la Teología de la liberación creer que Dios opta por los pobres hoy, y que esta opción se verifica en las acciones históricas de liberación de los pobres, es un hecho del que el teólogo no puede sustraerse sin quedar epistemológicamente imposibilitado de interpretar el "signo" de que se trata. Aquí la imparcialidad no sirve. Tampoco es creíble. Las otras teologías pueden aportar muchos conocimientos a la Teología de la liberación, y lo hacen. Pero si en definitiva ellas mismas no se confrontan con el Dios que en el pasado histórico se reveló en el Éxodo y en el Gólgota, orillan el quehacer propiamente teológico con riesgo de servir ideológicamente a intereses contrarios a los que moviliza a la Teología de la liberación. Esta exige al teólogo un compromiso personal, una "parcialidad", una praxis preteológica en favor de los pobres, como expresión de fe en un Dios que ama a los que los demás desprecian (18).

Los teólogos latinoamericanos toman distancia de la teología moderna europea, criticando su falta de arraigo histórico. Al presentar su propia teología, Gutiérrez roza las teologías primermundistas: "Hacer teología sin la mediación de la contemplación y de la práctica sería estar fuera de las exigencias del Dios de la Biblia" (19). Sin un compromiso creyente con los preferidos de Dios, no hay Teología de la liberación. Y así, al poner las cartas sobre la mesa, la Teología de la liberación exige a las otras teologías que expliciten al servicio de qué mundo, de qué Iglesia y de qué Dios están. Pues si la historia está en disputa, no es de extrañar que la idea de Dios y la teología en particular respondan a intereses divergentes (20).

(18) Afirma Sobrino: "Por qué la teología de la liberación hace de la irrupción de los pobres manifestación actual de la presencia y de la palabra de Dios y, por ello, fundamento de la teología es algo en último término preteológico" (Ibidem, p. 256).

(19) Gustavo Gutiérrez Hablar de Dios desde el sufrimiento del inocente, Sígueme, Salamanca, 1986, p. 17.

(20) Una de las principales contribuciones de Juan Luis Segundo a la teología de la liberación ha consistido en desmarcarla de la necesidad de probar la existencia de Dios, para concentrarla más bien en la de encontrar la imagen correcta de Dios, distinta de las imágenes idolátricas que se suelen hacer de él para manipular la realidad. Dice: "Puede parecer extraño, ilógico y hasta anacrónico el que nuestra obra, que trata sobre Dios, no comience preguntándose si Dios existe. Y qué pruebas o certidumbres tenemos de ello". "Por el contrario, nuestra reflexión comienza interesándose mucho más en la antítesis -aparentemente fuera de moda-fe-idolatría que en la -aparentemente actual-fe-ateísmo. Más aún, dejamos constancia desde la partida de que, en la antítesis que nos parece la más radical, fe-idolatría, quien se profesa cristiano puede ocupar cualquiera de las dos posiciones, así como el que se profesa ateo. En otras palabras, creemos que divide mucho más profundamente a los hombres la imagen que se hacen de Dios que el decidir luego si algo real corresponde o no a esa imagen" (Teología Abierta, Tomo II, Cristiandad, Madrid, 1983, p. 22). Este mismo planteamiento ilustrado de J.L. Segundo se haya en la cristología de Jon Sobrino. Para Sobrino todas las cristologías responden a intereses y, entre estos, hay que distinguir los que se ajustan a Cristo y los que mueven a tergiversarlo. Dicho con sus propias 
En este sentido la Teología de la liberación aporta un elemento importante para aclarar el concepto de "signo de los tiempos". Este es, que no es posible reflexionar acerca de ellos si no se "cree" en ellos, si al descubrir a Dios en ellos no se toma partido por la acción liberadora que en ellos Dios ejecuta. De lo contrario no tendría sentido alguno reflexionar sobre estos signos. Ellos reclaman una praxis, una acción espiritual, como prueba de reconocimiento de tal signo y de conversión al reino que anticipan. Pero también suponen un compromiso práctico y liberador como condición sin la cual tales signos no son percibidos.

Este aspecto distintivo de la comprensión del concepto de "signos de los tiempos" en América Latina, sin embargo, no ha podido eximir a la Teología de la liberación de fundamentar teológicamente el reto que ella misma asume. Este reto, veremos, ha llevado a la misma Teología de la liberación a un punto de crisis.

De momento nos detenemos en algunos supuestos teológicos básicos de la recepción latinoamericana de la categoría de los "signos de los tiempos".

\section{UNIDAD ESCATOLÓGICA DE LA HISTORIA}

La Teología de la Liberación tiene un concepto judeo-cristiano de la historia. La historia es una, tiene como único fin el reino de Dios y, en camino a este fin, ella avanza a través de una lucha dialéctica entre el Dios de la vida y los ídolos de la muerte (21). A las víctimas de la idolatría la Teología de la liberación les anuncia que su historia, contra todas las apariencias, tiene un sentido pues el reino del Dios de la vida es para ellas, aunque este reino no tendrá lugar más que a través del conflicto que genera la injusticia. Para la Teología de la liberación la unidad de la historia, su sentido, el reino que recapitula la voluntad de Dios para su creación, constituye una promesa escatológica a los que habitan en el reverso de la historia, luchando por su integración o simplemente padeciendo la exclusión.

La historia y el Reino de Dios anunciado por Jesús preferencialmente a los pobres, son dos aspectos de una sola realidad cuyo creador y realizador es un único y mismo Dios. De aquí que a la Teología de la liberación le sea más fácil afirmar que los "signos de los tiempos" son esencialmente signos mesiánicos que anticipan la consumación escatológica. Ellos indican en la dirección del reino y, sin embargo, no pueden agotar su realidad mientras la historia no alcance su fin. Aún así, la praxis mesiánica actual disipa la ambigüedad histórica. La ubicación en el "mundo de los pobres", viviendo anticipadamente las bienaventuranzas a ellos proclamadas, hace posible discernir mejor el sentido de la historia.

palabras "la cristología puede ser útil para cosas buenas, pero puede ser utilizada para cosas malas, lo cual no debiera extrañar, porque, siendo hecha por seres humanos, está también sujeta a la pecaminosidad y la manipulación. No hay que olvidar que en la historia ha habido cristologías heréticas que han recortado la verdad total de Cristo, y, lo que es peor, que ha habido cristologías objetivamente nocivas, que han presentado a un Cristo distinto y aun objetivamente contrario a Jesús de Nazaret. Recordemos que nuestro continente cristiano ha vivido siglos de opresión inhumana y anticristiana sin que la cristología, al parecer, se diera por enterada y sin que supusiera una denuncia profética en nombre de Jesucristo" (Jesucristo liberador, p. 13) Cf. Pablo Richard (ed.) La lucha de los dioses, San José, 1980. 
La Teología de la liberación se ha beneficiado de los avances teológicos del siglo XX. Ha heredado una comprensión escatológica de la historia y, además, la superación de la visión dualista que hasta hace poco oponía la historia mundana y la historia de la salvación. En la obra emblemática de Gustavo Gutiérrez Teología de la liberación, el autor sostiene que no hay dos, sino una sola historia (22). Esta historia nuestra puede y puede no ser también historia de Dios, anticipar o no anticipar su Reino. Pero el Reino no es algo distinto del mundo en que vivimos, sino este mismo mundo en la medida que se ajusta a la voluntad del Mesías que reina sobre la entera historia humana. Al afirmarse que la historia es una y que en ella y no otra parte Dios efectivamente está presente, actúa y llama, no se incurre en ningún tipo de monismo que induzca a pensar que la realidad es una con Dios sin distinción alguna. Ninguna fatalidad podría ser más perjudicial para los pobres que la que les lleve a pensar que el mal que padecen es tan "divino" como insuperable. La unidad de la historia en Dios según la Teología de la liberación exige que se respete la diferencia entre el Creador y la creación, y que se reconozca que el pecado personal y estructural divide a los hombres entre opresores y oprimidos. Pero la acción inmanente de Dios en el mundo excluye, a la vez, que se separe una historia sagrada de una historia profana como si esta pudiera de algún modo pararse sobre sus propios pies, prescindiendo de Él. Esta especie de "nestorianismo" escatológico paradójicamente amiga al progresismo moderno y a las promesas de salvación eterna, meramente futura, a los pobres. La liberación, el progreso como liberación de la miseria, se conservará eternamente en el reino prometido a los pobres (23). Pero el reino, a diferencia de la idea moderna del progreso, no banaliza la muerte actual de los pobres. Para el reino no hay "costo social" que valga.

La historia tiene un término. La injusticia terminará. Estamos en los tiempos finales entre el acontecimiento de Cristo y el día en que Cristo entregará el Reino al Padre. Si la teología contemporánea celebra "el paso, para cada uno y para todos, de condiciones de vida menos humanas a condiciones más humanas" (24), la Teología de la liberación recuerda, además, que las víctimas inocentes historizan al crucificado y la liberación de los pobres verifica la acción de Dios en Cristo en la medida que se los "baja de la cruz" (25). En uno y otro caso, los pobres hacen sacramentalmente presente a Cristo en una historia que se resolverá de su parte. En este sentido

(22) "Lo que hemos recordado en el párrafo precedente nos lleva a afirmar que, en concreto, no hay dos historias, una profana y otra sagrada 'yuxtapuestas' o 'estrechamente ligadas', sino un solo devenir humano asumido irreversiblemente por Cristo, Señor de la historia. Su obra redentora abarca todas las dimensiones de la existencia y la conduce a su pleno cumplimiento. La historia de la salvación es la entraña misma de la historia humana" (G. Gutiérrez, Teología de la liberación. Perspectivas, Sígueme, Salamanca, 1990, p. 194).

(23) Fredy Parra concluye: “...la comprensión escatológica de la historia es propia de la fe judeocristiana. Con todo lo dicho, la interpretación más adecuada de la historia y su sentido es la escatológica; es decir, la relación entre el reino anunciado y la historia no puede enunciarse en términos de monismo ni de dualismo. Se rechaza tanto los modelos de identidad como los que afirman la separación y radical no relación. En efecto, la esperanza escatológica mantiene abierta la historia al futuro y la convierte a la vez en el lugar donde se activa la promesa de Dios" (Samuel Yáñez y Diego García, o.c., p. 27).

(24) Populorum Progressio, 21.

(25) Cf. Jon Sobrino, La fe en Jesucristo, Trotta, Madrid, 1997, pp. 76-79. 
la Teología de la liberación es teología de una esperanza que toma en serio la muerte actual de los pobres. Habrá un juicio final de la historia en el que se revelará su inocencia. Pero esta esperanza no es alienante, sino que estimula a que los pobres sean sujetos de cambios sociales estructurales, y no simples personajes secundarios de sus propias vidas. En esto la Teología de la liberación es moderna. Pero rechaza que el progreso moderno condene a los pobres a una felicidad futura a costa de su sacrificio actual (26). Es hoy que los pobres son oprimidos por los ídolos, de los cuales la absolutización de la riqueza / propiedad privada estructural es el ídolo por excelencia (27). Hoy, sobre todo, que los pobres son liberados por el Padre de Jesucristo, tras la lucha en contra de los "dioses de la muerte" (28).

La Teología de la liberación subraya el carácter dialéctico de la culminación de la historia. Esta única historia no se teje simplemente con la acción de Dios y la acción del hombre en la medida que esta verifica la anterior, y como así se operara sobre tabula rasa. La acción de Dios en Cristo fue resistida. Jesús fue asesinado por anunciar a los pobres el reino de Dios. La historia está en disputa. Jon Sobrino habla de una "estructura teologal-idolátrica de la realidad", de acuerdo a la cual "(e)n la historia existe el verdadero Dios (de vida), su mediación (el reino) y su mediador (Jesús), y existen los ídolos (de muerte), su mediación (el antirreino) y sus mediadores (los opresores). Las realidades de ambos tipos no son solo distintas, sino aparecen formalmente en una disyuntiva duélica. Son, por tanto, excluyentes, no complementarias, y una hace contra la otra" (29).

La Teología de la liberación aporta a la comprensión general de los "signos de los tiempos" la dialéctica de la historia y la perspectiva de las víctimas. El reino prospera en contra del antirreino. No hay neutralidad posible. Sin embargo, la reducción de las diferencias humanas a una que contrapone a oprimidos y opresores, puede constituir una captación de los "signos de los tiempos" tan tajante que impida recuperar precisamente la unidad de la historia (30).

(26) Afirma Fernando Castillo: "Una teología de la praxis histórica se plantea necesariamente como instancia crítica frente a esta concepción elitista y autocomplaciente de la historia. Ella rechaza decididamente una visión de la historia como una sucesión de logros, incluso si estos son de carácter emancipatorio. La constitución del mundo moderno muestra que junto al camino de libertades individuales, sociales y políticas que van construyendo los hombres, va quedando también un reguero de víctimas de esa historia: son los vencidos y marginados" (Juan Noemi y Fernando Castillo Teología latinoamericana, Centro Ecuménico Diego de Medellín, Santiago, 1998, p. 114).

(27) Jon Sobrino, Jesucristo liberador, Trotta, Madrid, 1991, p. 241.

(28) La Teología de la liberación eleva a concepto la conflictividad humana. Una de sus temáticas más características es la de la lucha del Dios de la vida contra las divinidades de la muerte (cf. Jon Sobrino, o.c., p. 235-250.

(29) Jon Sobrino, o.c., p. 213.

(30) No hay duda que Jon Sobrino busca la unidad de la historia como reconciliación. A este efecto hacer ver como pocos autores la realidad del conflicto en la historia humana. Y precisamente porque toma en serio este conflicto como una realidad amenazante y destructiva, el conjunto de su sistema parece a veces desequilibrado (cf. Jorge Costadoat, "La liberación en la cristología de Jon Sobrino", Teología y Vida, Vol XLIV (2004), 62-84). 


\section{REVELACIÓN, DISCERNIMIENTO Y PRAXIS DE LIBERACIÓN}

La Teología de la liberación entiende que la revelación de Dios culmina en Jesús de Nazaret y su proyecto histórico del Reino. Esta manifestación de Dios en Cristo, en línea con la revelación de Dios en la historia de Israel, es perceptible como liberación para los pobres y perdón para los pecadores. Revelación y salvación para la teología contemporánea, y también para la Teología de la liberación, son la cara y el sello de una misma moneda. De aquí que los signos de "nuestro tiempo" haya que buscarlos allí donde la presencia y la voluntad de Dios se insinúan en acciones voluntarias capaces de transformar la realidad y también en la "pasión" de las víctimas (31). La liberación y, subcontrario, la opresión de los pobres es "signo de los tiempos". A veces los pobres luchan por su liberación. A veces pueblos enteros padecen una historia que se les impone.

Pero como la fe, la revelación y los "signos de los tiempos" van de la mano (32), los acontecimientos históricos en los que Dios interviene a través de las libertades no son evidentes para todos ni tampoco transforman necesariamente la realidad en la línea del reino. No es posible saber a ciencia cierta en qué grado las acciones humanas vehiculan la gracia o la rechazan, son auténticamente libres o responden a determinaciones psicológicas o sociológicas. De aquí que sea necesario un discernimiento de los "signos de los tiempos" (GS 4 y 11).

Este discernimiento exige inseparablemente, por una parte, reconocer las acciones propiamente espirituales a través de la cuales Dios se revela como un Dios liberador y, por otra, conocer las circunstancias socio-históricas de acuerdo al auxilio de las ciencias que, por lo demás, servirán para modificar la realidad a favor de los pobres.

No son "signos de los tiempos" los terremotos ni otros hechos de la naturaleza. Pudieran serlo, pero solo en la medida que dan lugar a acciones humanas. Hay "signos de los tiempos" donde hay acciones históricas, es decir, libres, voluntarias, intencionadas. Y de estas, tampoco cualesquiera. Solo aquellas que pueden ser identificadas como acciones "espirituales", acciones que son a la vez propias del Espíritu y de aquellos que actúan según el Espíritu. El Espíritu hace inmanente a Dios en la historia a través de acciones humanas que adquieren un valor trascendente que de suyo no tienen. En su trascendencia característica, el Espíritu no disputa al hombre la historia sino que, desde lo más interior de ella, la transforma (33).

(31) Según Fernando Castillo, “praxis histórica -y más precisamente- praxis de liberación no es solamente acción sino que tiene una dimensión pathica. La praxis de liberación se articula desde la solidaridad con los que sufren" (o.c., p. 116).

(32) Cf. Juan Luis Segundo "Revelación, fe, signos de los tiempos", Ignacio Ellacuría y Jon Sobrino (eds.) Mysterium Liberationis, Trotta, Madrid, 1990, pp. 443-466.

(33) En palabras de Pedro Trigo: "La acción del Espíritu también es trascendente. No es la acción de las fuerzas históricas. Nosotros no confundimos a Dios con los múltiples señores que rigen al mundo (1 Cor 8, 5-6), ni al Espíritu de Dios con la mano invisible del mercado o con el destino manifiesto de que se sienten portadores determinados pueblos o con el Estado ni tampoco con la institución eclesiástica. El Espíritu actúa desde la trascendencia; pero lo característico de la trascendencia del Espíritu es que es trascendencia en la inmanencia: mueve desde más adentro que lo íntimo nuestro. Mueve, no está. Mueve siempre y a todos y cada uno, es decir a cada uno como la persona única que es y como componente personalizado de los diversos conjuntos de los que forma parte. Pero como en el caso de Jesús, mueve liberando y habilitando, pero respetando el libre albedrío de quien no quiera actuar al impulso de esta libertad liberada" (Pedro Trigo, o.c., 42-43). 
La Teología de la liberación subraya que el discernimiento es necesario no solo porque unas acciones son espirituales y otras no. Las acciones que no son regidas por el Espíritu son regidas por un pecado social y cultural. Pedro Trigo, para estas últimas décadas, nos hablaría de acciones inducidas por el mercado totalitario, la figura histórica dominante de la época (34). La Teología de la liberación no desarrolla una demonología que pudiera empalmar con la visión apocalíptica propia de Jesús y sus contemporáneos para quienes los milagros fueron obra del Espíritu o de Beelzebul (cf. Mc 3, 22-30), pero se acerca. En su caso, como hemos visto, la acción de Dios compite en contra de aquellas acciones humanas idolátricas causantes del sufrimiento y de la muerte de los pobres.

Es así que el mismo Espíritu que opera acciones humanas libres que por su significación mayor llegan a constituir "signos de los tiempos", permite, como arriba está dicho, reconocer estos signos como obra de Dios. Por lo cual solo al final de la historia podremos saber en qué medida este discernimiento fue acertado, acaso contribuyó o no al reino. Según Pedro Trigo, "el resultado de las acciones más puras no es nunca el reino de Dios sino algo mejor que lo que había, aunque contaminado siempre con las imperfecciones de todo lo creado" (35). Mientras tanto los intérpretes de la voluntad divina pecarán casi inevitablemente de subjetivismo. Y si se trata de grados, habrá más obediencia al Espíritu, y menos subjetivismo, allí donde el discernimiento tenga como criterio fundamental de juicio el reino de Dios que Jesús inauguró por la fuerza del mismo Espíritu, también él bajo el régimen de la fe y del discernimiento. Los "signos de los tiempos" son signos mesiánicos. Mientras la historia no termine cargan con la ambigüedad de ser divinos o, en términos de la Teología de la liberación, de cumplir una función idolátrica o ideológica.

La apuesta de la Teología de la liberación es, sin embargo, aún más fuerte. Ella reclama una liberación de las estructuras de opresión convencida de la utilidad de las ciencias sociales tanto para conocer la realidad como para modificarla. Se trata de una teología católica en sentido estricto. Se inspira en la necesidad de mediar entre la fe y la razón. Esta mediación teórica, sin embargo, apunta derechamente a la mediación práctica de fe y justicia que es la que en definitiva importa. Anteponiendo la ortopraxis a la ortodoxia, la Teología de la liberación inclina la balanza del lado de acciones a la vez racionales y espirituales contrarias a aquellas que generan injusticia. La praxis inicial de solidaridad con los pobres constituye el lugar epistemológico correcto para descubrir la acción del Espíritu en los "signos de los tiempos". Esta praxis "espiritual", sin embargo, podrá cambiar efectivamente la realidad en la medida que se ajuste al criterio objetivo del reino del que nos habla la Escritura, pero también si pasa por la criba de las ciencias sociales que impedirán que el compromiso liberador se empantane en el fideísmo. El primado de la praxis en cuanto principio de conocimiento teológico reclama relevancia a la reflexión teológica.

(34) Cf. Pedro Trigo, En el mercado de Dios, un Dios más allá del mercado, Sal Terrae, Santander, 2003 , p. 203.

(35) Cf. ITER, o.c., p. 43. 
Esta tarea ha quedado pendiente. Por los años sesenta y setenta los teólogos latinoamericanos hallaron en teorías sociológicas como la de la "dependencia" un instrumento de análisis social y no faltó el teólogo que propuso el socialismo marxista como la fuerza política que debía cambiar las estructuras sociopolíticas. Después que la historia viró en la dirección del capitalismo en su versión neoliberal -que en América Latina operó como una acción estatal capaz de asegurar el predominio del libre mercado-, la Teología de la liberación ha tenido dificultades en encontrar las mediaciones racionales para que su fe en el Dios de los pobres se traduzca en su efectiva liberación. Desde entonces la Teología de la liberación ha seguido cursos distintos, alejándose a veces de su intención primera. La Teología de la liberación ha recuperado su honda motivación espiritual. Para Gustavo Gutiérrez, veinte años después de la obra mencionada, define aquella praxis histórica como la "espiritualidad" (36). No obstante la necesidad de este giro, ¿no se ha escamoteado así el imperativo de la liberación sociohistórica? En otra incursión, esta preocupante, la Teología de la liberación se ha parapetado en la denuncia profética, cegándose por principio a ver en las últimas transformaciones históricas avance alguno del Reino. De este modo se olvida que la salvación no es pura crítica, sino fundamentalmente creación. Y, por último, la Teología de la liberación ha ocupado bastante energía en la búsqueda de transformaciones eclesiales a favor de una "Iglesia de los pobres", para lo cual le ha sido a veces necesario denunciar el olvido del Vaticano II.

En otras palabras, sigue en pie la integración católica de fe y razón por la que la Teología de la liberación ha puesto las manos al fuego. A la fe en el Dios que opta por los pobres no le basta conocer la realidad de la miseria con instrumentos artesanales. Por cierto hoy no se tiene el optimismo típicamente moderno que tuvo la Teología de la liberación para creer que la historia, hecha por la libertad, podía ser cambiada a voluntad. Hemos caído en la cuenta de que el mundo se nos impone más de lo pensado (37). Pero mientras se siga esperando que Dios libere a los pobres, la búsqueda de tales mediaciones, es indispensable (38). Mientras la mediación científica no se haga, igual es posible una acción "artesanal". Pero la tarea queda pendiente, pues ha sido la misma Teología de la liberación la que la exige (39).

En suma, a pesar de las deficiencias señaladas, la teología contemporánea y la Iglesia se han beneficiado del redescubrimiento que el Teología de la liberación ha hecho de la fuerza liberadora del cristianismo y de la índole práctica de la teología cristiana.

(36) Gustavo Gutiérrez, Teología de la liberación, o.c., p. 36.

(37) Cf. Raúl González, "Variables en el discernimiento histórico", ITER No 33 (2004) 83-84.

(38) Paul Ricouer habla de la vía larga de la hermenéutica, lo cual nos indica que la tarea es compleja (Le conflit des interprétations. Essais d'herméneutique, Seuil, Paris, 1969, p. 260.

(39) Nos parece exagerada la opinión de Luis González-Carvajal cuando llama la atención "sobre el hecho de que, mientras no dispongamos de una sistema elaborado de interpretación, caeremos necesariamente en el subjetivismo. Cada uno verá en los signos de los tiempos la confirmación de sus propias ideas, porque, en el fondo, lo que oirá a través de los acontecimientos será su propia voz, no la de Dios" (Luis González-Carvajal, o.c., p. 60). ¿Acaso de la complejidad de un sistema de interpretación depende el discernimiento del Espíritu? Con todo, concordamos con él cuando afirma que "cuando el teólogo intenta indagar si un acontecimiento determinado puede ser considerado signo del Reino de Dios, lo menos que puede hacer es enterarse exactamente de en qué consiste ese conocimiento" (o.c., p. 63) 


\section{4. “EL SIGNO DE LOS TIEMPOS”: LA IRRUPCIÓN DEL POBRE}

Para Carlos Casale "un hecho es susceptible de convertirse en "signo de los tiempos' cuando, gracias a la toma de conciencia colectiva, está en condiciones de modificar en dirección mesiánica el equilibrio de las relaciones humanas de una determinada época". Pone un ejemplo: "La pobreza en la que se encuentran viviendo muchedumbres inmensas de hombres todavía no es, como tal, un 'signo de los tiempos'. Tampoco lo es cuando suscita un movimiento de solidaridad. La historia de la Iglesia está llena de testimonios de caridad para con los pobres, pero excepto quizás en los tiempos primitivos del franciscanismo, esto no ha supuesto una nueva consideración efectiva del Evangelio. Solo cuando algunos hombres comienzan a colocar la pobreza a la luz mesiánica y descubren un nuevo equilibrio en el Evangelio y en la Iglesia, para los cuales el misterio de la pobreza -en los pobres y en Cristo, que se hizo pobre- se convierte en el eje de la historia, el Evangelio se vuelve Evangelio de los pobres, y la Iglesia se vuelve Iglesia de los pobres... solo entonces comienzan los hombres a reconocer un signo de los tiempos" (40).

Pues bien, para los teólogos de la liberación la irrupción de los pobres en la sociedad y en la Iglesia, el "hecho mayor" de la época y de la realidad latinoamericana, representa para la Teología de la liberación "el signo de los tiempos" (41). Ellos fueron y son los destinatarios primeros del reino hecho presente mediante las palabras y las acciones de Jesús de Nazaret. Su liberación exige a la razón creyente elucidar transformaciones económicas, sociales y políticas. Ellacuría y Sobrino saben que otros signos son también posibles, pero aseguran que los pobres tienen tal importancia sacramental que donde se los halle se encontrará al Cristo que quiso ser reconocido en ellos y que lo que se haga por su liberación se lo hace por el reino (42). La historia también puede ser conocida desde su "reverso". Hay una "fuerza histórica de los pobres" que hunde sus raíces en la fe en el Dios crucificado. Más aún, para la teología de la liberación los "signos de los tiempos" se captan mejor

(40) O.c., p. 569.

(41) Jon Sobrino, "Los 'signos de los tiempos' en la Teología de la Liberación”, o.c., p. 254. Para Gustavo Gutiérrez la irrupción de los pobres, en cuanto "hecho mayor", en la medida que ha encontrado un lugar en la vida de la comunidad eclesial, "da lugar a una nueva manera de ser persona y creyente, de vivir y de pensar la fe, de ser convocado y de convocar en 'ecclesia'. Ese compromiso señala una línea divisoria entre dos experiencias, dos tiempos, dos mundos, dos lenguajes en América Latina y por consiguiente en la Iglesia latinoamericana" (Teología desde el reverso de la historia, 1982, p. 244. Esta obra fue publicada en Lima en 1977. Su primera parte, sin embargo, ha sido revisada y ampliada en la obra La fuerza histórica de los pobres (capítulo 9) Salamanca, 1982). A casi cuarenta años de Medellín, Carlos Schickendantz, ponderados los cambios en América Latina, afirma: "parece que los signos de los tiempos reconocidos en la segunda mitad de la década del sesenta y a comienzos de la década del setenta conservan hoy todo su valor, aunque adquieren matices y perspectivas nuevas" (J.O. Beozzo et al., o.c., p. 99-100). Ha variado la comprensión del pobre, pero su irrupción en la historia continúa siendo el gran signo de los tiempos del continente. Concluye Schickendantz: "Típico de las últimas décadas ha sido la emergencia pública de nuevos sujetos sociales largamente postergados: mujeres, indígenas, afroamericanos, mestizos de ambientes urbanos. En estos movimientos de autoconciencia y de dignificación, que reclaman una mayor sensibilidad por la alteridad y por el sufrimiento del otro, se pronuncian 'palabras de Dios' que actualizan el Evangelio y muestran caminos de compromiso ético-político” (p. 134).

(42) Cf. Jon Sobrino, o.c., p. 254. 
"desde los pobres de este mundo que desde cualquier otra realidad", pues Dios en ninguna otra realidad revela mejor su voluntad liberadora (43). Reconocemos con Carlos Schickendantz que al menos en la emergencia de nuevos sujetos sociales largamente olvidados, "es posible discernir uno de los signos de los tiempos más importantes para el cristianismo de nuestros días" (44).

La Teología de la liberación asegura que a ella se le ha dado advertir en la irrupción de los pobres la acción liberadora de Dios como un asunto de fe. Esto no la exime de dar razón de su fe. Sobrino explica qué hace razonable creer que Dios efectivamente tenga que ver con este acontecimiento (45). Pero la captación misma de este como revelación liberadora consiste en aquella experiencia creyente que funda la epistemología de la Teología de la liberación de la que hemos ya hablado. Aún más, la llamada a encontrar a Cristo en los pobres de Medellín, Puebla y Santo Domingo, y de la Teología de la liberación, representa la dimensión más profunda del cambio de paradigma arriba señalado (46). Pues ella tiene fuerza como para revolucionar completamente la teología y la Iglesia. ¿Qué será de la comprensión del Evangelio, de su traducción en enseñazas teológicas, espirituales, morales y litúrgicas cuando el lugar hermenéutico de interpretación sea el del "mundo de los pobres"? ¿Cómo habrá de ser una "Iglesia de los pobres” el día en que en ella los últimos sean efectivamente los primeros?

Este planteamiento -como lo fue el de Jesús que privilegió a las personas sobre doctrinas e instituciones-, trae aparejados sus propios problemas. Pensar la unidad de la historia no a partir de un concepto universal sino de la realidad concreta e irrepetible de los pobres, alteraría radicalmente la toma de decisiones que organizan la vida social y eclesial. No sin razón el incendio de la Teología de la liberación en la sociedad y en la Iglesia, ha sido apagado prontamente por los sectores ricos, poderosos y conservadores. La Teología de la liberación ha puesto en jaque el modo vertical de conseguir la unidad entre los hombres y ha sufrido la misma reacción uniformadora que ha sometido a los pobres por siglos. Ocurre que, incluso sin ánimo de perjudicar a los pobres, otros sectores han visto en sus planteamientos el principio de una revolución de enorme magnitud.

Esta dificultad, sin embargo, es propia de la teología de los "signos de los tiempos" en general. Si Dios trascendente es inmanente a la historia y en ella actúa y se revela con la originalidad creadora que solo Él tiene, la inversión metodológica de esta teología es alérgica a la comprensión metafísica de la realidad y afín a las aproximaciones fenomenológicas. Para la jerarquía de la Iglesia resulta doblemente desafiante e incluso amenazante, que Dios se identifique con los pobres y, más aún, si estos pobres pertenecen a otras tradiciones culturales y religiosas.

Subrepticiamente, sin embargo, cabe la posibilidad de que "el signo de los tiempos", los pobres, se convierta en una especie de principio metafísico que termine por monopolizar la revelación siempre nueva de Dios en la historia. Más de una vez la lectura de las obras de los teólogos de la liberación deja la impresión de haber

(43) Cf. Jon Sobrino, o.c., p. 269.

(44) Cf. J.O. Beozzo et al., o.c., p. 125.

(45) Cf. Jon Sobrino, o.c., pp. 256-260.

(46) Cf. Scannone, o.c., p. 32-33. 
convertido al pobre en un concepto abstracto que impide a la historia esa apertura que la tipifica como cristiana. Por ello, si es necesario poner las cosas en orden, hay que decir que, en sentido estricto, Jesús, el "signo de los tiempos" por antonomasia, no ha sido signo más que de "su" tiempo. Tampoco de la Iglesia se puede decir que ella constituya un signo del reino hasta el final de los tiempos. Lo es, en la medida que responde a las mociones del Espíritu. Y, por tanto, tampoco es necesario levantar a los pobres como un meta-signo de la actuación divina en la historia para garantizar que Dios opta por ellos. La Teología de la liberación no necesita traicionar su método, cerrar la historia a la novedad del Espíritu, para asegurar que los destinatarios del Evangelio hoy y siempre serán los pobres.

Al respetar su método, en cambio, la Teología de la liberación devuelve a la teología la modestia que nunca ha debido perder (47). Es una feliz coincidencia que esta teología, como los pobres que se abren paso en la vida con esfuerzo y humildad, renuncie a cerrar el sentido de la historia y, más bien, apueste, como cosa de fe, a que Dios probará que ama a los pobres. Así lo hizo con Job (48). Si a los pobres nadie puede decirles esto o aquello es lo que Dios quiere para ustedes; si tantas veces ni ellos mismos saben cómo rezar a un Dios que parece ignorarlos; si no tienen más que su fe para soportar la miseria, la teología, antes que darles respuestas, debe ayudarles a hacer sus preguntas. Pues es su fe la que les hace preguntar por qué. No por qué la Escritura dice tal o cual cosa, sino por qué si la Escritura dice que Dios es amor ellos son víctimas de un mal irreductible a cualquier explicación teológica. Para Gustavo Gutiérrez la teología responde a las siguientes preguntas: “ $¿(d)$ e qué manera hablar de un Dios que se revela como amor en una realidad marcada por la pobreza y la opresión? ¿Cómo anunciar el Dios de la vida a personas que sufren una muerte prematura e injusta? ¿Cómo reconocer el don gratuito de su amor y de su justicia desde el sufrimiento del inocente? ¿Con qué lenguaje decir a los que no son considerados personas que son hijas e hijos de Dios?" (49)

La Teología de la liberación toma en serio la presencia en la historia del mysterium inquitatis. El sentido de la historia es estrictamente cuestión de fe. El pobre latinoamericano es víctima de un mal que no se puede atribuir sin más a los ricos ni al "costo social" de las modernizaciones en tabla. A los pobres concretos, a su participación en el misterio pascual, ciertamente no a la metafísica, la teología debe la recuperación de la historia como una magnitud abierta al Espíritu hasta que Dios sea todo en todos $(1$, Cor 15,28$)$. La Teología de la liberación no tiene la solución de la injusticia del mundo, pero pareciera que es una teología que realmente la espera y la quiere.

(47) “... el cristiano no posee aún, ni siquiera por el hecho de entenderla, la verdad que Dios le comunica, mientras no consigue convertirla en 'diferencia' humanizadora dentro de la historia. Hasta que la ortopraxis se vuelva realidad, no importa cuán efímera y contingente sea, el cristiano no sabe todavía la verdad" (Juan Luis Segundo, o.c, p. 448).

(48) Cf. G. Gutiérrez, Hablar de Dios desde el sufrimiento del inocente, Sígueme, Salamanca, 1986.

(49) G. Gutiérrez, o.c., pp. 18-19. 


\title{
RESUMEN
}

La Teología de la liberación recibe el Concilio Vaticano II de un modo creativo precisamente porque, a semejanza de Gaudium et Spes que pone a la Iglesia a la escucha de la voz de Dios en la historia, ella nace de una Iglesia que reconoce en los pobres del continente un llamado divino a su liberación. "Los signos de los tiempos" representan para la Iglesia continental, y para la Teología de la liberación particularmente, un modo de ubicarse en su propio mundo latinoamericano en busca de la presencia y de la voluntad de Dios. En este artículo se destaca la importancia de los "signos de los tiempos" para el método de la Teología de la liberación; se explicitan los principales supuestos teológicos de esta teología; y se remata con el que sería el "signo de los tiempos" en América Latina, la irrupción de los pobres.

Palabras clave: Teología de la liberación, "Signos de los tiempos", Método teológico, Revelación.

\begin{abstract}
The Theology of Liberation receives Vatican II in a creative manner, precisely because, in a way similar to Gaudium et Spes, which puts the Church on alert to the voice of God in history, the Theology of Liberation is born out of a Church that recognizes in the poor of the Latin American continent a divine call for its liberation. "The signs of the times" represent, for the continental Church, and for the Theology of Liberation in particular, a way of placing oneself within one's own Latin American world, in search of the presence and the will of God. In this article, the importance of the "signs of the times" for the method of the Theology of Liberation is underlined, the principal theological suppositions of this theology are examined, and it finishes off with what would be the "sign of the times" in Latin America, the irruption of the poor.
\end{abstract}

Key words: Theology of Liberation, "Signs of the Times", Theological method, Revelation. 